\title{
COULTHARD, M. \& CALDAS-COULTHARD, C. R. (EDS.) TEXTS AND PRACTICES. LONDRES: ROUTLEDGE, 1996, 294 PÁGS.
}

\author{
Resenhado por: \\ Clarissa H. F. de Lima Gomes
}

O livro é dividido em duas partes: a primeira parte é uma coletânea de artigos que dissertam sobre a teoria crítica do discurso. O primeiro artigo de Roger Fowler defende a língua como uma prática social de acordo com a visão de Althusser de que "a língua como prática social é uma intervenção na ordem econômica e social”. Contudo, o autor questiona o termo crítico utilizado pela Lingüística Crítica (LC). Por que crítico? Para Fowler, há duas definições do termo crítico: a) Crítico - denota uma reflexão sobre um sistema de restrições que só é produzido pelo ser humano, distorcendo pressões sobre os indivíduos ou sobre um grupo ou sobre uma raça como um todo, não resistindo ao processo da formação do "eu", b) Crítico - é corroborar o objeto da experiência cuja "objetividade" é posta em questão, crítico supõe que há um degrau de deformidade que mascara a realidade. Portanto, crítico procura remover esta distorção e, portanto, fazer a liberação do que tem sido distorcido. Na visão do autor, essas definições são negativas e militantes. Fowler discorda da Lingüística Crítica porque ela objetiva desmascarar as representações sociais realizadas por meio da linguagem pelas instituições sociais. Para o teórico, não há uma realidade verdadeira que possa ser desvelada pela prática crítica, pois o que existe é uma relativa variação de representações.

De acordo com Fowler, a teoria da Lingüística Crítica é uma teoria de representação, ou seja, estuda a linguagem como "semiótico-social". Os objetivos dessa teoria estão de acordo com os da sociologia crítica. A mencionada teoria se preocupa em utilizar a análise lingüística para expor as representações e discriminações dos diversos modelos do discurso público como: a leitura crítica de jornais, de propaganda política, documentos oficiais dentre outros. Em relação ao discurso público, os objetivos da presente teoria estão desfamiliarizados e ela não é lingüística em tudo. A 
Lingüística Funcional constitui um suporte teórico, intelectual e político para a Lingüística Crítica. Para o autor, o que falta para a teoria crítica é um modelo teórico e metodológico compacto. É necessário desenvolver e consolidar esse modelo. O autor faz uma observação sobre a questão da ideologia que, para ele, é onipresente nos textos, mas as análises publicadas sobre a mesma não têm sido suficientes. Outra observação é que as categorias analíticas de Halliday como a transitividade, a nominalização precisam ser explicadas de forma clara e sem o uso da palavras do próprio Halliday.

Já o artigo de Gunther Kress argumenta que a Lingüística Crítica e a Análise de Discurso Crítica desde o seu início têm um projeto político: a expansão do discurso que altera a desigual distribuição dos bens econômicos, culturais e políticos nas sociedades contemporanêas. Kress critica a L C por se preocupar com a recepção e a leitura orientadas, desprezando a produção ou os produtores. Para o autor, se os recursos lingüísticos, culturais e econômicos constituem e formam a subjetividade do indivíduo e estão distribuídos, desigualmente, por meio da classe, do gênero, da idade, da profissão, da raça, da religião. Tudo isso deve ser objeto de estudo da Lingüística Crítica. O artigo de Kress demonstra que o currículo escolar inglês é um esboço de um sujeito social. Tal documento é um conjunto de conhecimentos, habilidades, significados, valores que contam a experiência de vida das pessoas. Neste documento, os estudantes constroem, reconstroem e transformam a sua subjetividade.

Para o autor, o indivíduo utiliza determinados recursos para a construção de sua subjetividade. Um exemplo é a mídia. A representação da mídia é feita por meio da linguagem escrita e falada, por imagens visuais, fotografias, gestos, desenhos, dentre outros, que limitam a mídia como meio de comunicação de massa e, ao mesmo tempo, constituem recursos representacionais constituídos de tecnologias específicas. Kress investigou como a produção de recursos representacionais do sujeito transforma a sua subjetividade. Nesse sentido, o autor analisou a primeira página do jornal Frankfurter Allgemeine, no qual há recursos de representação da linguagem verbal. Para o autor, todos os textos são multi-semióticos e, no mencionado jornal, há os aspectos do layout e características tipográficas (entre outros). 
Dessa forma, o conjunto dessas características semióticas - isto é, recursos representacionais - sugere uma particular disposição, ou seja, uma produção de um certo tipo de subjetividade orientada para uma certa racionalidade. Esses recursos representacionais caracterizam um leitor particular, assim como, um produtor particular. Recursos como estes sustentam a subjetividade tanto do produtor quanto do leitor. Assim, o leitor habitual do Frankfurter Allgemeine sente-se feliz e confortável com o jornal porque há uma homologia entre a sua subjetividade e a organização semiótica do texto.

Por outro lado, o artigo de Theo Van Leeuwen investiga como os atores sociais são representados no discurso. Para a Análise de Discurso Crítica, a importância reside no fato de que os atores sociais podem ser representados como agentes ou pacientes. $\mathrm{O}$ autor investiga a representação dos atores sociais em um artigo intitulado "A odisséia das raças", do jornal australiano Sydney Morning. O artigo analisa a representação da prática social da imigração como algo institucionalizado na Austrália, assim como outras representações de práticas sociais que servem para legitimála: as práticas de escrita das comissões governamentais que falam sobre a imigração ou a condução das pesquisas de opinião pública sobre o assunto. Todas estas práticas envolvem um conjunto de atores sociais, mas a representação deles no artigo nem sempre é incluída pelo fato de o jornal ser conservador e destinar-se ao público da classe média.

As representações incluem ou excluem os atores sociais para preencher os interesses dos leitores do jornal. Algumas exclusões são "inocentes", detalhes que os leitores já conhecem e que são irrelevantes, por exemplo: "Manter a polícia é árduo". Neste exemplo, o ator responsável pela manutenção da polícia é excluído. $\mathrm{O}$ autor apresenta os vários recursos que são utilizados pelos artigos de jornais para representar os atores sociais, como por exemplo: a) ativação - ocorre quando os atores sociais são representados como ativos; b) apassivação - ocorre quando os atores sociais são representados como passivos; c) generalização - ocorre quando se utiliza um referente genérico para representar atores sociais; d) especificação - quando se utiliza um referente específico para representar os atores sociais. Agora, o artigo de Norman Fairclough argumenta que as ordens discursivas estão tornando-se profundamente afetadas pelo fenô- 
meno da tecnologização do discurso que é a incorporação de formas institucionais e de práticas que são sistematicamente constituídas de: a) profundo estudo das práticas discursivas de instituições e de locais de trabalho; b) esboço de uma prática discursiva, de acordo com as estratégias e os objetivos institucionais; c) treinamento do pessoal em cada esboço da prática discursiva. Fairclough define a tecnologização do discurso como uma institucionalização de redes que conectam a pesquisa, o esboço e o treinamento das práticas discursivas das instituições sociais. O treinamento e a educação da linguagem são discutidos separadamente. A tecnologização do discurso envolve: 1) a emergência dos tecnólogos do discurso; 2) uma mudança na política das práticas discursivas; 3) o esboço e a projeção das técnicas discursivas; 4) uma simulação estrategicamente simulada no discurso; e 5) uma pressão para padronizar as práticas discursivas. Os tecnólogos do discurso são cientistas sociais ou outros tipos de consultores que têm acesso à informação científica e as suas intervenções na prática discursiva são "a verdade". A relação deles com as instituições são de empregados ou consultores que trazem um treinamento específico para as diversas práticas discursivas de uma empresa. Esses tecnólogos do discurso desenham e redesenham as técnicas discursivas como a entrevista, a leitura ou o aconselhamento para maximizar a sua eficácia e mudá-las afetivamente. Uma das conseqüências desse fenômeno é que as ordens contemporâneas do discurso têm sido afetadas e têm mudado a vida social. Uma das mudanças é a aplicação de tecnologias do governo no ambiente de trabalho para implementar programas de treinamento que mudem as relações sociais no trabalho que, por sua vez, afetam as identidades sociais e profissionais. Um exemplo de tecnologização do discurso é o treinamento de professores das instituições de ensino por meio de cursos de extensão que mandam os professores mudarem suas práticas discursivas como a leitura, a organização de seminários, propostas de pesquisa (dentre outros). Finalizando a primeira parte do livro, o artigo de Teun Van Dijk defende que um dos pontos principais da Análise de Discurso Crítica é relatar a relação entre o discurso e o poder social. A ADC deve descrever e explicar como o poder é representado, reproduzido e legitimado pelo discurso dos grupos dominantes. Van Dijk defende que o poder tem as seguintes características: 1) é uma propriedade das 
relações entre os grupos sociais, as instituições e as organizações; 2) o poder social é definido em termos de controle exercido por um grupo ou uma organização sobre as ações e mentes de outro grupo, limitando a liberdade de ação dos outros, ou influenciando seu conhecimento, atitudes ou ideologias; 3) o poder específico de um grupo ou de uma instituição pode ser distribuído e pode ser restringido para um domínio social, como para o domínio político, o da mídia, o do direito, o da educação (dentre outros); 4) o domínio é uma forma de abuso do poder social que é moralmente ou legalmente legitimado pelo exercício de controle sobre os outros; 5) o poder é baseado no acesso privilegiado dos recursos sociais como a riqueza, empregos e o acesso preferencial para o discurso público e o da comunicação. De acordo com Van Dijk, um dos maiores elementos que reproduzem o poder e o domínio é o acesso ao discurso e aos eventos comunicativos. O acesso pode ser analisado em termos de tópicos ou referentes do discurso, ou seja, quem escreve ou fala sobre algo. Por exemplo, no sistema educacional os professores, controlam os eventos comunicativos, distribuem os turnos de fala e, ao mesmo tempo, têm acesso especial para controlar o discurso educacional. Por outro lado, os estudantes têm, em princípio, o acesso para falar em salas de aula somente quando são convidados para falar.

$\mathrm{Na}$ segunda parte do livro, os artigos ensinam como aplicar a LC na análise de textos. O primeiro artigo, de Ruth Wodak, fala sobre o discurso racista contra estrangeiros na Áustria, apresentado nos noticiários e jornais do mencionado país. Wodak mostra que há duas definições de racismo: a) racismo como o discurso da diferença que é compreendido como uma prática racista que serve para estabelecer práticas sociais, políticas e econômicas que excluem certos grupos das fontes simbólicas e materiais; b) o racismo como hostilidade contra estrangeiros. A autora afirma que a mídia na Áustria representa os estrangeiros, como os romenos e turcos, como invasores e vítimas.

No papel de vítima, tanto os romenos como os turcos são vistos como vítimas dos problemas sócio-políticos de seus países de origem que vão para a Áustria buscar asilo. Na opinião da autora, a mídia aproveitase do papel de vítima desses imigrantes para construir o discurso da simpatia e da tutela. O discurso da simpatia se caracteriza pela simpatia das 
autoridades austríacas em relação à situação sócio-econômica difícil dos imigrantes no país. Já o discurso da tutela se caracteriza pela avaliação dos políticos austríacos em como inaugurar uma real democracia na Romênia. Quando os turcos e os romenos são vistos como invasores, a mídia representa-os por meio do discurso econômico. O discurso econômico se caracteriza por mostrar que os romenos vão para a Áustria em busca de melhores condições sócio-econômicas de vida. Dessa forma, a solução para o Governo Austríaco é auxiliar financeiramente a Romênia. Nesse sentido, Wodak mostra que a construção da identidade é um processo de diferenciação no qual ocorre a descrição de um determinado grupo e, simultaneamente, a separação deste grupo em relação a outros. Quando a imprensa austríaca faz uma representação dos romenos e de outros imigrantes por meio dos discursos da tutelagem, da simpatia e da economia, na verdade, ela está construindo a identidade do povo austríaco por meio do discurso da diferenciação em relação a outros povos. Já os artigos de Ramesh Krish e Michael Hoey falam sobre como são definidas as palavras étnico, tribo, homem, mulher, de acordo com o dicionário COBUILD ${ }^{1}$. De acordo com Krish, a definição de étnico no COBUILD é: "étnico - relacionase com um grupo humano que tem características religiosas, lingüísticas e raciais em comum". De acordo com o autor, a extensão dos termos usados nestas definições é certamente confusa, ou mesmo, sofisticada para um falante nativo do inglês. Conceitos como raça, religião, linguagem, cultura, imigração, assimilação, nação e sociedade são difíceis para compreender como etnicidade. Krish compara as definições de étnico de outros dicionários e percebe que eles sugerem que as formas derivadas e compostas da palavra étnico têm um status acadêmico, científico ou técnico. A palavra étnico sempre está associada com grupos, minorias e com atividades como a violência e a limpeza. Por outro lado, a palavra racial nos dicionários para aprendizes inclui conceitos negativos como: a violência e a limpeza e relaciona-se com conceitos como: a violência, a discriminação, o preconceito, o assédio, o conflito e o ódio. O conceito da palavra tribo relacionase com organizações, como em assembléias, líderes e chefes. A palavra

\footnotetext{
${ }^{1}$ The Collins English Dictionary, que possui 18 milhões de palavras coletadas de textos modernos do inglês.
} 
tribo tem um conceito pejorativo porque se refere a conflitos, lutas, violência e guerra. Krish atenta (o leitor) para quem patrocina os usos das palavras étnico, racial e tribal. $\mathrm{O}$ autor alerta que essas palavras representam a identidade do(a) falante ou do escritor(a) no contexto em que ocorrem. E quantos usuários desses termos podem ser descritos como étnicos, tribais ou raciais por esses patrocinadores? São questões e conceitos que precisam ser pensados e revisados. O artigo de Michael Hoey mostra a análise das definições de homem e mulher no dicionário COBUILD. A análise demonstra o que existe, implicitamente, nas definições de palavras como, por exemplo: "ser humano - é um homem de ambos os sexos". Essa definição revela a assimetria entre o conceito de homem e de mulher, ou seja, as mulheres são consideradas como uma sub-classe do homem. A língua trata o conceito de homem como não-marcado e o de mulher como marcado, por exemplo: "homem da rua - é uma pessoa comum que não é rica ou educada ou famosa"; "mulher da rua - prostituta".

O artigo de Malcolm Coulthard nos revela a manipulação do escrivão no discurso de depoimento do preso. O procedimento se caracteriza por dois policiais que conduzem o interrogatório, um faz perguntas e o outro escreve as perguntas e respostas do preso. Para Coulthard, este procedimento põe a polícia em uma posição privilegiada, pois ela pode inventar outra versão do preso e excluir determinados trechos. O autor verificou que o escrivão ao reportar o discurso do acusado, na verdade, reporta-o de acordo com sua versão. Malcolm comparou o discurso falado e o discurso reportado e, percebeu diferenças. Para o autor, a Análise de Discurso Crítica deve descrever e explicar como o abuso de poder é representado, reproduzido ou legitimado pelo texto e pela fala dos grupos dominantes das instituições sociais.

Já o artigo de Branca Telles Ribeiro fala sobre o discurso psiquiátrico. Para Ribeiro, o paciente quando consulta um médico-psiquiatra utiliza um discurso do mundo da medicina. Ribeiro analisou uma consulta psiquiátrica na qual o médico faz uso do discurso informal para obter mais informações sobre o paciente e, depois, distancia-se do paciente por meio do discurso formal. Nesse sentido, Ribeiro mostra que o paciente percebe essa mudança no discurso do médico e, em seguida, procura mudar sua posição no discurso ou prefere continuar na posição anterior. Essa per- 
cepção do paciente sobre a mudança no discurso médico é chamada de "dicas contextualizadoras", de acordo com a concepção de Gumperz. Para a autora, a análise da consulta revela que enquanto o médico controla o que acontece no mundo da medicina, o paciente busca controlar o que ocorre no mundo da vida. O que revela uma assimetria no discurso entre o médico e o paciente.

O artigo de Dino Preti fala sobre a representação da face no discurso da terceira idade. $\mathrm{O}$ autor verificou que os idosos quando entrevistados por jovens sentem-se inseguros e procuram preservar a sua face. Nesse sentido, o autor utiliza o conceito de face de Goffman. O conceito de face (de Goffman) relaciona-se com a performance social, ou seja, com a imagem do "eu" que cada um procura manter na conversação. O conceito de face elaborado por Goffman pode ser entendido como a imagem pública que um indivíduo constrói e tenta preservar em seu meio social. Em resumo, é a imagem que o indivíduo externa e que é compartilhada pelos outros. O indivíduo procura manter a sua face no seu meio social, isto é, por meio de uma luta travada com outros indivíduos para obter a aprovação de seus interlocutores ao longo do processo interacional. O princípio de preservação da face é determinado pela necessidade que o indivíduo tem para ser aceito por seu grupo social.

Dessa maneira, o autor verificou que as pessoas da terceira idade preservam a sua face quando entrevistadas por jovens. Os indivíduos da terceira idade usam a face positiva e a negativa diante deles. De acordo com Goffman, a face positiva significa o desejo do indivíduo de ser apreciado e aprovado pelos outros. Já a face negativa é usada pelo indivíduo para manter o desejo de autonomia, não sofrer imposição dos outros. As entrevistas analisadas por Preti revelam que os idosos utilizam a face positiva para serem aceitos pelo público jovem e não se sentirem excluídos. Outros idosos já utilizam a face negativa com o intuito de preservarem seus valores e não permitir que os jovens ridicularizem as suas tradições. Dessa forma, Preti percebe que os idosos possuem uma grande preocupação em manter uma boa imagem diante dos jovens.

O artigo de Val Gough e Mary Talbot fala sobre a construção da subjetividade heterossexual em uma coluna do jornal inglês Sunday Mirror, na qual uma sexóloga, Marje Proops, dá conselhos para assuntos como: 
sexualidade, casamento (entre outros). Os autores analisam uma carta publicada no mencionado jornal de um homem casado que fala sobre as suas experiências sexuais com um amigo de infância, em seguida, seu reencontro com o amigo, ambos já casados. A carta do homem revela que ele está confuso sobre a sua sexualidade. A sexóloga escreve uma cartaresposta, na qual ela mostra que aventura sexual na infância de meninos com outros meninos é normal e isso não implica que o mencionado homem seja homossexual. Os autores verificaram que a sexóloga constrói uma identidade heterossexual para esse homem. Dessa maneira, os autores percebem que as experiências homossexuais masculinas são legitimadas para o público masculino. Enquanto para a sexóloga, essa experiência sexual de meninos com outros meninos é uma fase transitória para o desenvolvimento da heterossexualidade do homem.

Por outro lado, o artigo de Andrew Morrison fala sobre a representação, nos jornais de Zimbábue, da hegemonia masculina contra a prática da bestialidade por parte de prostitutas Zimbábues. As reportagens analisadas mostram o espanto de autoridades políticas e da sociedade, em geral, sobre a prática da bestialidade pelas prostitutas. O autor revela que a bestialidade quando praticada por homens não causa espanto. Agora, quando essa prática envolve mulheres causa espanto e indignação. De acordo com Morrison, a indignação e o espanto contra as prostitutas revelam a hegemonia masculina contra as experiências sexuais femininas. Já o artigo de Carmem Rosa Caldas-Coulthard fala sobre as experiências sexuais de mulheres casadas com garotos de programas, relatadas na revista Marie Claire brasileira. Na revista, a autora faz uma análise discursiva e verifica que as mulheres casadas, ao revelarem suas experiências sexuais, procuram usar pseudônimos e assumir o papel de vítimas. Como vítimas, elas justificam que os maridos não lhes dão a devida atenção e, por isso buscam garotos de programa. Para a autora, a sociedade brasileira olha para esse tipo de conduta como uma transgressão em relação àquela visão tradicional da mulher casada. Enquanto a conduta dos homens casados que buscam aventuras sexuais fora do casamento é vista como algo natural na sociedade. O que revela uma hegemonia masculina em relação às experiências sexuais femininas fora do casamento. 
Finalizando, o mencionado livro vem a ser uma contribuição para a compreensão da Teoria Crítica do Discurso e como aplicá-la na análise de textos públicos como jornais, noticiários e artigos de revistas, entre outros. A Lingüística Crítica tem sido alvo de críticas por teóricos de outras áreas, mas ela revela e desnuda as relações de poder que estão presentes nos discursos institucionais e orienta àqueles que se encontram numa posição desfavorável no discurso a sair dessa posição. 